\section{The Technological Advancement for Planning, Navigation and Robotic Assistance for Skull Base Surgery}

\author{
Dennis Adjepong,MD,MBA ${ }^{1}$ and Kwaku Amoateng ${ }^{2}$ (D) \\ ${ }^{1}$ Department of Neurological Surgery, California Institute of Behavioral Neuro- \\ sciences \& Psychology, Fairfield, USA \\ ${ }^{2}$ University of Medicine \&Pharmacy of Targus Mures, Transylvania, Romania
}

\begin{abstract}
An image-guided robot system for skull-base surgery facilitates the planning of surgical station and navigation, and determination of the path be taken by the removal tool, which follows the robotic manipulator. This study focuses on the development of an integrated system for robotics, navigation, and planning assistance using an image-guided robot system for skull-base drilling. The mechanism is effective in providing access to neurosurgical interventions; for example, in the case of tumor resection. The motivation for this study is to identify how surgeons can use robots to maintain and improve safety and prevent accidental damage to critical neurovascular structures that might occur during the drilling process. Data obtained from a systematic and formative review of existing research, as well as evaluation of current experimental studies, will be used to determine the effectiveness and success rate of image-guided robotic surgery.

Keywords: Image-guided surgery; Navigation System; Robotic assistance; Skull-base drilling
\end{abstract}

\section{Introduction}

Recently, Robots have shown effectiveness in assisting surgeons in performing various bone milling and drilling procedures [1]. One of the common examples is the commercial systems used for replacement and joint repair surgeries within Vitro feasibility, as in the case of mastoidectomy [2,3]. While performing the procedure, the robot

${ }^{*}$ Corresponding author: Dennis Adjepong, Department of Neurological Surgery, California Institute of Behavioral Neurosciences \& Psychology, Fairfield, USA, Tel: +1 5712771998; E-mail: adjepongdennis1@gmail.com

Citation: Adjepong D, Amoateng K (2020) The Technological Advancement for Planning, Navigation and Robotic Assistance for Skull Base Surgery. J Surg Curr Trend Innov 4: 042.

Received: May 26, 2020; Accepted: June 17, 2020; Published: July 24, 2020

Copyright: ( 2020 Adjepong D, et al. This is an open-access article distributed under the terms of the Creative Commons Attribution License, which permits unrestricted use, distribution, and reproduction in any medium, provided the original author and source are credited. follows a path guided by the CT image, which has registered the physical anatomy of the surgical site in the operating room that is, in turn, transferred to the robot [4]. In the field of cranial and neurosurgery, there has also been advanced technological innovation [5]. For example, the introduction of neuro-endoscopy, modern neuroimaging, operating microscope, stereotactic surgery image-guided surgery, and technologically demanding implants has contributed to the advancement and also challenging the human dexterity limits [6]. Robotic-assisted surgery in skull-based drilling is motivated by image-guided surgery, and its suitability is enhanced due to the critical nature of adjacent anatomy, complex anatomical components, and static nature of the skull [7]. Complications in the craniotomies for the brain tumors that occur in the deep posterior, middle, and anterior cranial fossae results in the need for complicated removal of the bone for complete tumor resection [8].

\section{Methods}

The literature review performed on Cochrane, Medline, and PubMed databases as well as specialist journals on skull-base drilling and robotic surgery. Some of the keywords used for the search included robotic surgery, image-guided procedure, cranial base surgery, and skull base robotics. The study did not use any selection criterion; all articles with relevant information on the research topic were reviewed, which provided a broad scope. However, articles concerning augmented reality, simulation, and navigation were excluded from the analysis since they were not considered as techniques for skull base robotics.

\section{Results}

The studies revealed that using image-guided robotic assistance for skull base surgery minimized complications and adverse events of hand surgery [9]. Surgeons can comfortably control the tool motion using different mechanics, including foot pedal or joysticks, which increases precision [10]. Compared to surgeries without robotic assistance, the setup time for image-guided skull base surgery was relatively long, but with improved accuracy [11]. For instance, when used on patients undergoing endoscopic skull base surgery, none of the individuals developed side effects such as synechia or acute sinusitis $[12,13]$ (Table 1).

\section{Discussion}

Although there has been continuous development in the field of robotics, no robot is currently used routinely in skull base surgery [16]. Many researchers have focused their studies on developing approaches such as the da Vinci robot that provides access to skull base; however, none of the proposed solutions have been viable for use on living subjects due to the invasive nature of the procedures [17].

Nevertheless, skull base robotic surgery is state of the art for most pathologies, and it is of high importance in carrying out borderline interventions for neck and head surgeries as well as managing skull base defects that might occur after transnasal surgery [18]. 
Citation: Adjepong D, Amoateng K (2020) The Technological Advancement for Planning, Navigation and Robotic Assistance for Skull Base Surgery. J Surg Curr Trend Innov 4: 042 .

\begin{tabular}{|c|c|c|c|c|l|}
\hline Author name (s) & Year of development & Robot name & Type of Instrument & Type of control & Safety \\
\hline Bumm, et al. [14] & 2005 & Evolution 1 & Endoscope & $\begin{array}{l}\text { Guides surgical operations by flexibly inspecting } \\
\text { gastrointestinal tract and biological duct. }\end{array}$ & $\begin{array}{l}\text { Drill the head's skull and also make larger incisions. } \\
\text { They are also used to drill away bones during sur- } \\
\text { gery. }\end{array}$ \\
\hline Xia, et al. [5] & 2008 & None & Endoscope or Drill & Co-manipulation & $\begin{array}{l}\text { Cooling convectional tools helping in surgery or } \\
\text { spine, head, and extremities near soft tissues. }\end{array}$ \\
\hline Wurm, et al. [15] & 2005 & A-73 & $\begin{array}{l}\text { Operating channels, } \\
\text { drill, and endoscope }\end{array}$ & Joystick & $\begin{array}{l}\text { Record video and take pictures during surgery. It also } \\
\text { controls suctioning at lower intestinal endoscopy. }\end{array}$ \\
\hline Mattheis, et al. [12] & 2019 & None & Fndoscope & Foot pedal &
\end{tabular}

Table 1: Showing innovationin integratedrobotic assistance system in skull base surgery.

Since the approval of the da Vinci Surgical System by the Food and Drug Administration, there has been an increase in transoral surgical modalities for neck and head tumors [19,20]. Flexible robotic systems have also been optimized for use in transoral surgery [21]. However, despite the improvement of these systems, the da Vinci Robots cannot be used in skull base surgery due to the size of the machines, especially for use in endonasal surgery [18].

Xia et al. suggested the use of a cooperatively-controlled robotic system due to its feasibility in a clinical setting [5]. The experiments showed that the controlled robot system minimizes the placement and dimension error, improving accuracy in the machining process [22]. Implementation of the prototype in a clinical setting requires engineering effort and high investment, which has been a hindrance to its usage $[23,24]$. However, robotic surgery in skull base drilling would have been beneficial as well as in endoscopic guiding systems [25]. Methods such as the 4-hand technique, which is part of the implementation for the skull base surgery routine, could also be used with the endoscopic guiding systems [21]. Various prototypes, including Nimsky et al., with their Evolution 1 robotic system, have been developed, but the information on their clinical application is missing [14].

The study identified various barriers to the successful implementation of robotics in surgery, which included inadequate knowledge of the operative technique by the robotic engineers [9]. This challenge is caused by the difficulty of surgeons to express their needs, hence resulting in the limitation of current robots in terms of their machine/ man control, controls, and active perception [26]. Therefore, to overcome these challenges, there is a need for collaboration between the surgeons and surgical robot laboratories to help engineers understand the physical properties and the anatomy of the tissues that the robot will be in contact with [16]. Engineers must also develop innovative designs and architecture with miniaturizing components, adapted to work cooperatively in the operative procedures, and interfaces that facilitate safety and meet the surgical environment requirements $[20,27,28]$.

\section{Unanswered Questions}

Some of the missing components identified while performing this study are the issue of ergonomy [29]. With the existing commercial robots, there is a gap in how they will be suited to meet the usability needs of the surgeons and the rate of the learning curve for the tested robots [30,31]. The research was also limited to skull base surgery; therefore, it does not provide conclusive information on how other mechanisms such as endoscope surgery have improved the image-guided procedures using robotic guidance system [14].

\section{Conclusion}

Robot-assisted skull base surgery is an important technique that enhances the capacities of the surgeons and also saves on time. Therefore, there is a need to develop a dedicated robot with strict specifications on the operation procedure in terms of safety, ergonomy, and dimensions. The different experimental protocol has shown promising progress in the development of robotic assistance skull base surgery and other cases such as lamina papyracea, optic nerve, and internal carotid artery. Robotics are necessary for helping with the extension of indications of the anterior skull base surgery; however, the complications with existing prototypes, as discussed in the literature, present a challenge to its successful implementation. Robotic based surgeries are effective, and they should be optimized to have advanced control units to improve usability and safety. Surgical robots should provide a programmable digital platform that allows integration with preoperative $3 \mathrm{D}$ planning data from MRI or CT scans. This process enables familiarization of the robot with surgical aims, determination of landmarks, and identification of the surgical corridor. This safety measure reduces unwanted complications and tissue damage.

\section{References}

1. Siebold MA, Dillon NP, Webster III RJ, Fitzpatrick JM (2015) Incorporating target registration error into robotic bone milling. Proc SPIE Int Soc Opt Eng 9415: 94150.

2. Razavi CR, Wilkening PR, Yin R, Barber SR, Taylor RH, et al. (2019) Image-Guided Mastoidectomy with a Cooperatively Controlled ENT Microsurgery Robot. Otolaryngology-Head and Neck Surgery 161: 852-855.

3. Madani O, Rau T, Eilers H, Baron S, Lenarz T, et al. (2007) Robot-Assisted Surgery at the Lateral Skull Base. Skull Base 17: 213.

4. Kong X, Duan X, Wang Y (2016) An integrated system for planning, navigation and robotic assistance for mandible reconstruction surgery. Intelligent Service Robotics 9: 113-121.

5. Xia T, Baird C, Jallo G, Hayes K, Nakajima N, et al. (2008) An integrated system for planning, navigation and robotic assistance for skull base surgery. Int J Med Robot 4: 321-330.

6. Matinfar M, Baird C, Batouli A, Clatterbuck R, Kazanzides P (2007) Robot-assisted skull base surgery. IEEE Pg No: 865-870.

7. Haidegger T, Kazanzides P, Benyó B, Benyó Z (2012) Event-based patient motion detection and compensation in image-guided robotics. IEEE Pg No: 841-846.

8. Siebold MA, Dillon NP, Fichera L, Labadie RF, Webster III RJ, et al. (2017) Safety margins in robotic bone milling: from registration uncertainty to statistically safe surgeries. Int J Med Robot 13: 1773. 
Citation: Adjepong D, Amoateng K (2020) The Technological Advancement for Planning, Navigation and Robotic Assistance for Skull Base Surgery. J Surg Curr Trend Innov 4: 042.

9. Dillon NP, Balachandran R, Fitzpatrick JM, Siebold MA, Labadie RF, et al. (2015) A compact, bone-attached robot for mastoidectomy. Journal of medical devices 9: 310031-310037.

10. Haidegger T, Győri S, Benyó B, Benyó Z (2010) A stochastic approach to error estimation for image-guided robotic systems. Conf Proc IEEE Eng Med Biol Soc 2010: 984-987.

11. Friedrich DT, Scheithauer MO, Greve J, Hoffmann TK, Schuler PJ (2017) Recent advances in robot-assisted head and neck surgery. Int J Med Robot 13.

12. Mattheis S, Schlüter A, Stähr K, Holtmann L, Höing B, et al. (2019) Firs Use of a New Robotic Endoscope Guiding System in Endoscopic Orbital Decompression. SAGE, California, USA.

13. Li QH, Zamorano L, Pandya A, Perez R, Gong J, et al. (2002) The application accuracy of the NeuroMate robot - a quantitative comparison with frameless and frame-based surgical localization systems. Computer-Aided Surgery 7: 90-98.

14. Bumm K, Wurm J, Rachinger J, Dannenmann T, Bohr C, et al. (2005) An automated robotic approach with redundant navigation for minimal invasive extended transsphenoidal skull base surgery. min-Minimally Invasive Neurosurgery 48: 159-164.

15. Wurm J, Bumm K, Steinhart H, Vogele M, Schaaf HG, et al. (2005) Development of an active robot system for multi-modal paranasal sinus surgery. Europe PMC 53: 446-454.

16. Kupferman ME, Hanna E (2017) Robotic surgery of the skull base. In: Gil Z, Amit M, Kupferman ME (eds.). Atlas of Head and Neck Robotic Surgery, Springer International Publishing, New York City, USA.

17. Shen W, Gu J, Milios E (2004) Robotic neurosurgery and clinical applications. IEEE Pg No: 114-119.

18. Trévillot V, Garrel R, Dombre E, Poignet P, Sobral R, et al. (2013) Robotic endoscopic sinus and skull base surgery: a review of the literature and future prospects. Eur Ann Otorhinolaryngol Head Neck Dis 130: 201-207.

19. Brodie J, Eljamel S (2011) Evaluation of a neurosurgical robotic system to make accurate burr holes. Int J Med Robot 7: 101-106.

20. Hanna EY, Holsinger C, DeMonte F, Kupferman M (2007) Robotic endoscopic surgery of the skull base: a novel surgical approach. Arch Otolaryngol Head Neck Surg 133: 1209-1214.
21. Chung YC (2012) Prototype Development of a Robotic System for Skull Drilling. Korean Journal of Computational Design and Engineering 17: 198-207.

22. Friedrich DT, Sommer F, Scheithauer MO, Greve J, Hoffmann TK, et al. (2017) An innovate robotic endoscope guidance system for transnasal sinus and skull base surgery: proof of concept. J Neurol Surg B Skull Base 78: $466-472$.

23. Pott PP, Scharf HP, Schwarz ML (2005) Today's state of the art in surgical robotics. Computer-Aided Surgery 10: 101-132.

24. Dillon NP, Kratchman LB, Dietrich MS, Labadie RF, Webster III RJ, et al (2013) An experimental evaluation of the force requirements for robotic mastoidectomy. Otol Neurotol 34: 93-102.

25. Campbell RG (2019) Robotic surgery of the anterior skull base. Int Forum Allergy Rhinol 9: 1508-1514.

26. Villaret AB, Doglietto F, Carobbio A, Schreiber A, Panini C, et al. (2017) Robotic Transnasal Endoscopic Skull Base Surgery: Systematic Review of the Literature and Report of a Novel Prototype for a Hybrid System (Brescia Endoscope Assistant Robotic Holder). World neurosurgery 105: $875-883$.

27. Schneider JS, Burgner J, Webster III RJ, Russell III PT (2013) Robotic surgery for the sinuses and skull base: what are the possibilities and what are the obstacles? Curr Opin Otolaryngol Head Neck Surg 21: 11-16.

28. O’Malley BW, Weinstein GS (2007) Robotic skull base surgery: preclinical investigations to human clinical application. Arch Otolaryngol Head Neck Surg 133: 1215-1219.

29. O’Malley Jr BW, Weinstein GS (2007) Robotic anterior and midline skull base surgery: preclinical investigations. Int J Radiat Oncol Biol Phys 69: 125-128.

30. Moya-Plana A, Bresson D, Missistrano A, Temam S, Gorphe P (2019) Multiportal Approach to Skull Base Combining Endoscopic Transnasal Surgery and Transoral Robotic Surgery with Da Vinci Xi System: Feasibility Assessment and Clinical Cases. Journal of Neurological Surgery Part B: Skull Base 80: 157

31. Hachem RA, Rangarajan S, Beer-Furlan A, Prevedello D, Ozer E, et al. (2017) The role of robotic surgery in sinonasal and ventral skull base malignancy. Otolaryngol Clin North Am 50: 385-395. 


\section{di \\ нетан}

Advances In Industrial Biotechnology | ISSN: 2639-5665

Advances In Microbiology Research | ISSN: 2689-694X

Archives Of Surgery And Surgical Education | ISSN: 2689-3126

Archives Of Urology

Archives Of Zoological Studies | ISSN: 2640-7779

Current Trends Medical And Biological Engineering

International Journal Of Case Reports And Therapeutic Studies | ISSN: 2689-310X

Journal Of Addiction \& Addictive Disorders | ISSN: 2578-7276

Journal Of Agronomy \& Agricultural Science | ISSN: 2689-8292

Journal Of AIDS Clinical Research \& STDs | ISSN: 2572-7370

Journal Of Alcoholism Drug Abuse \& Substance Dependence | ISSN: 2572-9594

Journal Of Allergy Disorders \& Therapy | ISSN: 2470-749X

Journal Of Alternative Complementary \& Integrative Medicine | ISSN: 2470-7562

Journal Of Alzheimers \& Neurodegenerative Diseases | ISSN: 2572-9608

Journal Of Anesthesia \& Clinical Care | ISSN: 2378-8879

Journal Of Angiology \& Vascular Surgery | ISSN: 2572-7397

Journal Of Animal Research \& Veterinary Science | ISSN: 2639-3751

Journal Of Aquaculture \& Fisheries | ISSN: 2576-5523

Journal Of Atmospheric \& Earth Sciences | ISSN: 2689-8780

Journal Of Biotech Research \& Biochemistry

Journal Of Brain \& Neuroscience Research

Journal Of Cancer Biology \& Treatment | ISSN: 2470-7546

Journal Of Cardiology Study \& Research | ISSN: 2640-768X

Journal Of Cell Biology \& Cell Metabolism | ISSN: 2381-1943

Journal Of Clinical Dermatology \& Therapy | ISSN: 2378-8771

Journal Of Clinical Immunology \& Immunotherapy | ISSN: 2378-8844

Journal Of Clinical Studies \& Medical Case Reports | ISSN: 2378-8801

Journal Of Community Medicine \& Public Health Care | ISSN: 2381-1978

Journal Of Cytology \& Tissue Biology | ISSN: 2378-9107

Journal Of Dairy Research \& Technology | ISSN: 2688-9315

Journal Of Dentistry Oral Health \& Cosmesis | ISSN: 2473-6783

Journal Of Diabetes \& Metabolic Disorders | ISSN: 2381-201X

Journal Of Emergency Medicine Trauma \& Surgical Care | ISSN: 2378-8798

Journal Of Environmental Science Current Research | ISSN: 2643-5020

Journal Of Food Science \& Nutrition | ISSN: 2470-1076

Journal Of Forensic Legal \& Investigative Sciences | ISSN: 2473-733X

Journal Of Gastroenterology \& Hepatology Research | ISSN: 2574-2566
Journal Of Genetics \& Genomic Sciences | ISSN: 2574-2485

Journal Of Gerontology \& Geriatric Medicine | ISSN: 2381-8662

Journal Of Hematology Blood Transfusion \& Disorders | ISSN: 2572-2999

Journal Of Hospice \& Palliative Medical Care

Journal Of Human Endocrinology | ISSN: 2572-9640

Journal Of Infectious \& Non Infectious Diseases | ISSN: 2381-8654

Journal Of Internal Medicine \& Primary Healthcare | ISSN: 2574-2493

Journal Of Light \& Laser Current Trends

Journal Of Medicine Study \& Research | ISSN: 2639-5657

Journal Of Modern Chemical Sciences

Journal Of Nanotechnology Nanomedicine \& Nanobiotechnology | ISSN: 2381-2044

Journal Of Neonatology \& Clinical Pediatrics | ISSN: 2378-878X

Journal Of Nephrology \& Renal Therapy | ISSN: 2473-7313

Journal Of Non Invasive Vascular Investigation | ISSN: 2572-7400

Journal Of Nuclear Medicine Radiology \& Radiation Therapy | ISSN: 2572-7419

Journal Of Obesity \& Weight Loss | ISSN: 2473-7372

Journal Of Ophthalmology \& Clinical Research | ISSN: 2378-8887

Journal Of Orthopedic Research \& Physiotherapy | ISSN: 2381-2052

Journal Of Otolaryngology Head \& Neck Surgery | ISSN: 2573-010X

Journal Of Pathology Clinical \& Medical Research

Journal Of Pharmacology Pharmaceutics \& Pharmacovigilance | ISSN: 2639-5649

Journal Of Physical Medicine Rehabilitation \& Disabilities | ISSN: 2381-8670

Journal Of Plant Science Current Research | ISSN: 2639-3743

Journal Of Practical \& Professional Nursing | ISSN: 2639-5681

Journal Of Protein Research \& Bioinformatics

Journal Of Psychiatry Depression \& Anxiety | ISSN: 2573-0150

Journal Of Pulmonary Medicine \& Respiratory Research | ISSN: 2573-0177

Journal Of Reproductive Medicine Gynaecology \& Obstetrics | ISSN: 2574-2574

Journal Of Stem Cells Research Development \& Therapy | ISSN: 2381-2060

Journal Of Surgery Current Trends \& Innovations | ISSN: 2578-7284

Journal Of Toxicology Current Research | ISSN: 2639-3735

Journal Of Translational Science And Research

Journal Of Vaccines Research \& Vaccination | ISSN: 2573-0193

Journal Of Virology \& Antivirals

Sports Medicine And Injury Care Journal | ISSN: 2689-8829

Trends In Anatomy \& Physiology | ISSN: 2640-7752

Submit Your Manuscript: https://www.heraldopenaccess.us/submit-manuscript 